\title{
Comparing Different Serious Games Strategies for Teaching the SCRUM Framework
}

\author{
Djenane Cristina Silveira Santos, Federal University of Itajubá, \\ djenane@unifei.edu.br, https://orcid.org/0000-0001-7216-3595 \\ Adler Diniz de Souza, Federal University of Itajubá, \\ https://orcid.org/0000-0002-9393-398X \\ Melise Veiga Paula, Federal University of Itajubá, melisepaula@gmail.com, \\ https://orcid.org/0000-0002-0412-8840
}

\begin{abstract}
Access to new technologies is slowly changing classrooms and their dynamics. Gamification has been a widely used approach, and its benefits are still being studied. This paper aims to present a serious game which assists in teaching the SCRUM (software development) framework in higher education disciplines. For this, a virtual game has been created containing two different ways of playing, and its performance as a support tool to traditional teaching methodologies has been analyzed. Through a planned experiment, it was possible to identify a direct positive impact on students' Learning Gain.
\end{abstract}

Keywords: gamification, project management, scrum framework, serious game.

\section{Comparando Diferentes Estratégias de Jogos Sérios para Ensino do Framework SCRUM}

Resumo: O acesso às novas tecnologias está mudando lentamente as salas de aula e sua dinâmica. A gamificação tem sido uma abordagem amplamente utilizada e seus benefícios ainda estão sendo estudados. Este artigo tem como objetivo apresentar um jogo sério que auxilia no ensino do framework SCRUM (desenvolvimento de software) em disciplinas do ensino superior. Para isso, foi criado um jogo virtual e foi analisado o seu desempenho como ferramenta de apoio às metodologias tradicionais de ensino. Por meio de um experimento planejado foi possível identificar um impacto positivo direto no Ganho de Aprendizagem dos alunos.

Palavras-chave: gamificação, gerenciamento de projetos, framework scrum, jogos sérios.

\section{Introduction}

According to NewZoo (2020), of the total players, 23.0\% are between 10 and 20 years old, $27.3 \%$ between 21 and 30 years old, $23.0 \%$ between 31 and 40 years old, $16.7 \%$ between 41 and 50 years old and $10.0 \%$ between 51 and 65 years old. Given the above, it is relevant to pay attention to the relationship that is established between students and video games and how video games can contribute to the learning of these students.

There are a growing number of studies that recognize the importance of learning based on digital games, that is, the use of games for educational purposes. As Vlachopoulos and Makri (2017) states, in recent years, several empirical studies have been published investigating the effects of serious games on learning outcomes, and there is significant interest from the scientific and educational community, including instructors and those who create educational policies. It is generally assumed that digital educational games can positively contribute to students' academic knowledge because through active V. $19 \mathrm{~N}^{\circ} 1$, julho, 2021 
learning and immediate feedback, more effective learning is achieved (Vanbecelaere et al., 2020).

According to Morsi and Mull (2015), the traditional teaching methods used in higher education, which include lectures and laboratory classes, no longer meet the natural behavior through which students learn, which is making use of the new technologies available.

The objective of this work is to present the creation of a virtual game capable of assisting in teaching the Scrum framework and compare it with other serious game, which uses a different game strategy (board game). Its development used key concepts of gamification and serious game techniques, and its improvement was accomplished through theoretical game design concepts. We also present an analysis of its impact on their learning gain compared to the traditional teaching methodology. The main contribution of this work is to test two different strategies of serious games, to compare them with each other, and also to compare them with the traditional teaching methodology.

This work presents in the next sections the key concepts, the creation of the Scrum in Space game, the mini-games assessment methodology and results and, finally, the conclusion.

\section{Gamification, Serious Games and Game Design}

In order to guarantee a correct execution of the game's adaptation for an educational environment, it is necessary to know and understand the advantages and limits of the direct application of gamification.

Serious games are designed with specific intentions, often with the objective of supporting teaching and transmitting some scientific or cultural knowledge. According to Gee (2009), serious games are not limited to the pure popular form of entertainment but involve learning the types of domains (for example, history, geography, urban planning), skills, or content that we associate with school, work, health, citizenship, knowledge, construction, or community.

Kapp (2012) states that it is important to consider four fundamental elements of a game: (i) abstraction: it presents a different reality, with only a few characteristics of real-life; (ii) challenges: keep the player active in pursuit of a specific objective; (iii) rules: define the structure of the game; (iv) feedbacks: guide the player through positive or negative stimuli.

Werbach and Hunter (2012) identify three types of game elements as applicable categories to the studies and development of gamification, namely dynamics, mechanics, and components.

The dynamics represent the highest level of abstraction and involve the themes, aspects, and interactions present in the game. They are in the background of the game and are therefore not explained. These are the most polished and qualitative sphere in the game.

Mechanics refer to the elements that lead to actions and justify them. They serve as a guideline and limit for players' actions. They are also responsible for guiding the player, giving meaning to each of his actions. Each mechanic is a way to achieve one or more dynamics.

The components are the specific applications viewed and used in the game interface. It represents the most concrete level of the elements and can be linked to one or more mechanics of the game. They are the tools with which players interact with the game and are often the focus of much rework to suit the target audience. The combination

experimentation with different dynamics, mechanics, and components is the task of the game designer and represents his ability to solidify the final product. 


\section{Creation SCRUM in Space}

SCRUM in Space and the choice of discipline that would be worked on in the game were inspired by the work done by Souza et al. (2017). Aiming to contribute to the process of training students of Software Project Management, Souza et al. (2017) presents the development and validation of a serious electronic board game called SCRUMI for teaching concepts inherent to the SCRUM framework.

SCRUM in Space is a game that consists of two challenging mini-games, Sprint and Survival, based on their own mechanics and a question and answer system, aiming to evaluate part of the concepts of the Scrum framework in order to serve as an extra tool in their teaching. Dividing the game into different mini-games has been presented as a more appropriate approach because, with shorter playing time, players' attention is gained more by the difficulty of completing stages than by the desire to reach the end of the game itself. The Scrum framework steps have been split between the phases of the two mini-games to show the game's ability to easily cover different topics.

The project's main motivator was the creation of a game that would attract higher education students, who already have some kind of experience with virtual games. The dynamics should contain more mature themes, mechanics with more challenging difficulties and components more suited to university routines.

\subsection{Mini Sprint Game}

The motivation for creating the first mini-game, called Sprint, came from the trend of the mobile game market "endless runner", which consists of a reflex game where a character must dodge various obstacles in a race of dynamic difficulty. It is a three-stage laser obstacle racing game with a "true or false" question system. The game dynamics are presented on the home screen in a text format.

An incentive for the right answers lies in changing the speed of the laser chasing the player. In order to create a challenging scenario, the laser speed is slightly changed at each step, regardless of hit or miss. But at each error, the speed increases further.

Another important factor is the difficulty of each halfway among questions. It is essential for the player to feel the difficulty escalating as he becomes familiar with the controls and game playing. Each line of obstacles was placed in the game for the purpose of demonstrating a staggering difficulty, as shown in Figure 1(a).

When a question point, called a safe point, is reached, the laser is frozen to allow for timely reading, analysis, and response by the player. In case of an incorrect answer, a message is shown justifying why the choice was wrong. Along with the justification is the warning that the laser has been further accelerated due to incorrect response.

If players fail to reach the safe point of the questions or dodge obstacles, the laser hits them, and they die instantly. The game over screen is then displayed, providing the options to restart the phase or return to the main menu.

It is noteworthy that each phase of the mini-game refers to phases of the Scrum framework, which are: preparation, analysis, and execution. For each phase, a different visual identity is assigned. A phase ends when players are able to answer all three questions and reach the end of the course, where the characters' ship is located for taking them away. Players are then taken to the beginning of the next phase of Sprint, where they shall have to take part in the challenge again and answer new questions.

A scoring system was introduced in order for players not only to be motivated to play for a certain reward but also to assess the final result of the time played. In this system, the players start with a thousand points that decrease over time. This way, the longer the players take to complete the phase, the lower their final score. In addition, for each correct answer, the players receive 100 points as a reward. And as a punishment for a wrong answer, the players lose 100 points. 


\subsection{Mini Survival Game}

The second mini-game, Survival, is a game where the players must constantly look for resources that keep them alive for a longer period of time and still fight against auto-moving enemies and answer multiple-choice questions. The game dynamics are presented on the home screen in a text format.

In the game theme, a scenario was used where the characters' ship needs to make an emergency landing on an unknown location. The players need to get fuel to continue the trip. This fuel is highlighted as soon as it appears in the scenario, as shown in Figure 1(b). As the character seeks to gather fuel, the enemies, with adaptive movement autonomy, pursue the player in a coherent manner, dodging the scenario obstacles, and presenting a real danger to the character's life.

At every four fuels won, the game is paused, and a new interface is presented to the players, showing a question followed by four options. Similar to Sprint, feedback is instantaneous as soon as the players select the alternative, with messages indicating whether the answer is correct or incorrect, and justifying if the chosen alternative is incorrect.

In order to exemplify the possibility of an arbitrary number of questions, three questions have been posed from each step of the Scrum framework (to cover each step similar to the Sprint game).

The endgame state is obtained either by answering all questions or when the character's life is over. In the second case, an explosion similar to that in Sprint serves as instant visual feedback. The Score system has been implemented in Survival in the same way as in Sprint.

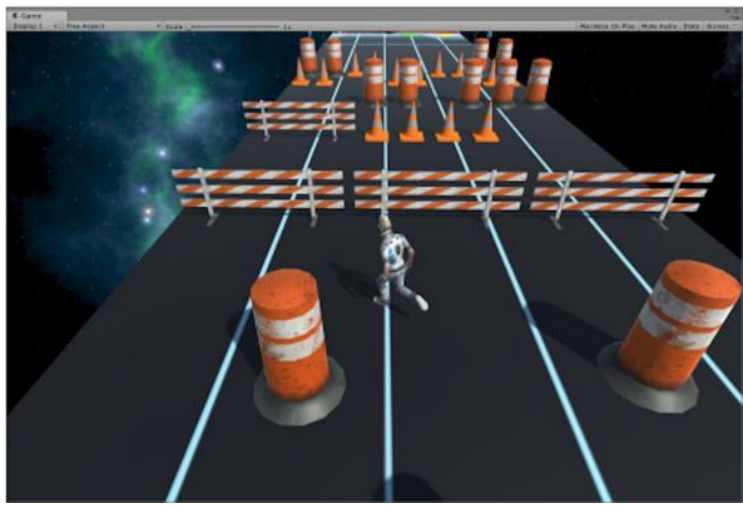

(a) A set of obstacles on the first course of the Sprint mini-game

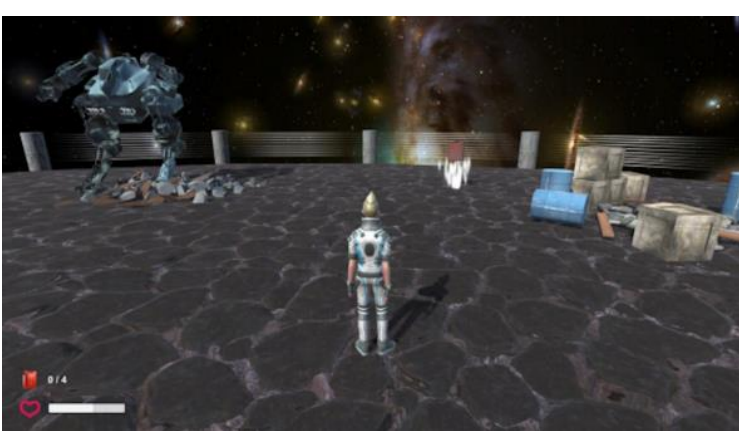

(b) Fuel highlighted in the Survival mini-game scenario

Figure 1 - Scrum in Space mini-games

\section{Mini games assessment methodology and results}

SCRUM In Space and its intention to serve as a support tool for classrooms and standard teaching have been evaluated was done by means of an experiment designed to measure learning gain by means of the game and compare it to the traditional teaching methodology and also to the Scrumi game. The players and evaluators were students of the Software Project Management discipline at the Federal University of Itajubá, among them undergraduates in Information Systems (SIN) and Science Computer (CCO).

\subsection{Experiment Planning}

The validation of the game by means of the planned experiment is based on three-hypothesis pairs, based on students' Learning Gain exposed to different learning 
methodologies.

\subsubsection{Scope of the Experiment}

Analyzing the SCRUM in Space game against the SCRUMI game and traditional classes for the purpose of evaluating regarding students' Learning Gain from researchers' point of view in the context of the Software Project Management discipline taught to students of Undergraduate Information Systems (SIN) and Science Computer (CCO) courses.

\subsubsection{Experiment Planning - Hypotheses Formulation}

The hypotheses defined were the following:

First Hypothesis: aim to identify if there were students' knowledge gain, or if the students hit more questions in the SCRUM framework questionnaire after had a traditional class.

- HO $\mathbf{O}_{T T M}$ Before $x$ tTM After: The students submitted to Traditional Teaching Methodologies (TTM) had HIGHER OR EQUAL Learning Gain AFTER had a class.

Learning Gain $=\%$ of Test Hits Before a Class $-\%$ of Test Hits After a Class $>=0$

- H1 $1_{T T M}$ Before $x$ TTM After: The students submitted to Traditional Teaching Methodologies (TTM) had LOWER Learning Gain AFTER had a Class. Learning Gain $=\%$ of Test Hits Before a Class $-\%$ of Test Hits After a Class $<0$

Second Hypothesis: aim to identify if there were students' knowledge gain, or if the students hit more questions in the SCRUM framework questionnaire after had a traditional class AND had played the Scrum in Space (SIP) serious game.

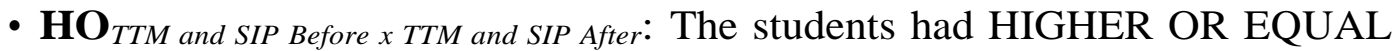
Learning Gain AFTER submitted to Traditional Teaching Methodologies (TTM) and had played the serious game Scrum in Space (SIP).

Learning Gain $=\%$ of Test Hits Before had a Class and played SIP - \% of Test Hits After had a Class and played SIP $>=0$

- H1 $1_{T T M}$ and SIP Before $x$ TTM and SIP After: The students had LOWER Learning Gain AFTER submitted to Traditional Teaching Methodologies (TTM) and had played the serious game Scrum in Space (SIP).

Learning Gain $=\%$ of Test Hits Before had a Class and played SIP - \% of Test Hits After had a Class and played SIP $<0$

Third Hypothesis: aim to identify if there were students' knowledge gain, or if the students hit more questions in the SCRUM framework questionnaire after had a traditional class AND had played the SCRUMI serious game.

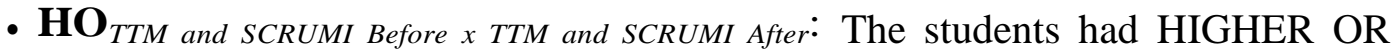
EQUAL Learning Gain AFTER submitted to Traditional Teaching Methodologies (TTM) and had played the serious game SCRUMI.

Learning Gain $=\%$ of Test Hits Before had a Class and played SCRUMI - \% of Test Hits After had a Class and played SCRUMI $>=0$

- H1 $1_{T T M}$ and SCRUMI Before $x$ TTM and SCRUMI After: The students had LOWER Learning Gain AFTER submitted to Traditional Teaching Methodologies (TTM) and had played the serious game SCRUMI. 
Learning Gain $=\%$ of Test Hits Before had a Class and played SCRUMI - \% of Test Hits After had a Class and played SCRUMI $<0$

After it, 3 other hypotheses were defined aim to compare the treatments proposed between them. These hypotheses are the following:

Treatment 01: A comparison between the serious game SCRUM in Space (SIP) versus Traditional Teaching Methodologies (TTM)

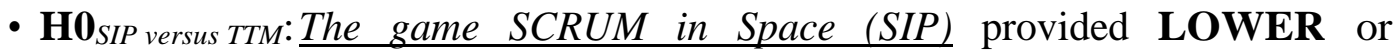
EQUAL Learning Gain from the SCRUM Framework regarding the Traditional Teaching Methodologies (TTM) for undergraduate students of SIN and CCO courses.

Learning Gain $=\%$ of Test Hits SIP $-\%$ of Test Hits TTM $<=0$

- H1 $1_{\text {SIP versus TTM: }}$ The game SCRUM in Space (SIP) provided HIGHER Learning Gain from the SCRUM Framework regarding the Traditional Teaching Methodologies (TTM) for undergraduate students of SIN and CCO courses.

Learning Gain $=\%$ of Test Hits SIP $-\%$ of Test Hits TTM $>0$

Treatment 02: A comparison between the serious game SCRUM in Space (SIP) versus serious game SCRUMI

- H0 SIP versus SCRUMI: The game SCRUM in Space (SIP) provided LOWER or EQUAL Learning Gain from the SCRUM Framework regarding the

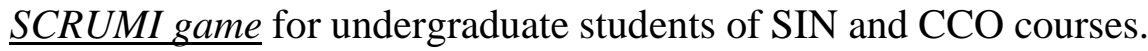

Learning Gain $=\%$ of Test Hits SIP $-\%$ of Test Hits SCRUMI $<=0$

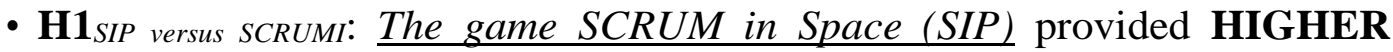
Learning Gain from the SCRUM Framework regarding the SCRUMI game for undergraduate students of SIN and CCO courses.

Learning Gain $=\%$ of Test Hits SIP $-\%$ of Test Hits SCRUMI $>0$

Treatment 03: A comparison between the serious game SCRUM in Space (SIP) and the serious game SCRUMI versus Traditional Teaching Methodologies (TTM)

- H0 Serious Games versus TTM: The game SCRUM in Space (SIP), together with SCRUMI game has provided LOWER or EQUAL Learning Gain from the SCRUM Framework regarding the Traditional Teaching Method- ologies (TTM) for undergraduate students of SIN and CCO courses.

Learning Gain $=\%$ of Test Hits Games $-\%$ of Test Hits TTM $<=0$

- H1 $1_{\text {Serious Games versus TTM: }}$ The game SCRUM in Space (SIP), together with SCRUMI game has provided HIGHER Learning Gain from the SCRUM Framework regarding the Traditional Teaching Methodologies (TTM) for undergraduate students of SIN and CCO courses.

Learning Gain $=\%$ of Test Hits Games $-\%$ of Test Hits TTM $>0$

\subsection{Description of the Experiment}

The efficiency of the serious game SCRUM in Space (Treatment 01), the board serious game SCRUMI (Treatment 02), and the Traditional Classes (Treatment 03) have been assessed regarding Learning Gain by means of an experiment.

This experiment has had three distinct steps that were: (i) INTRODUCTORY SCRUM methodology CLASS by means of the Traditional Teaching Methodologies, (ii) PRESENTATION of the teaching tools to be mentioned (a) Virtual game SCRUM 
in Space and (b) Scrumi board game and (ii) ASSESSMENT of the different Teaching approaches.

In order to measure students' learning gain (experiment subjects) in the Scrum methodology, they responded to a short general knowledge test on the Scrum methodology BEFORE and AFTER being subjected to the teaching methodology studied. The percentage of students' success in the tests is considered the dependent variable.

For conduct the experiments it was used the Random Sampling technique to define what students are going to use each game. Initially, 33 students participated in the experiment and due to the sample size being considered insufficient, a second experiment, with 40 students, was carried out under the same conditions, totaling 73 students.

The classes in which the first experiment was conducted had 33 Science Computer and Information Systems students, and in this way, the students were distributed into 3 groups the following way: Group 1: composed by 9 undergraduates students which would use SCRUMI board game, Group 2: composed by 8 undergraduates students which would use SCRUM IN SPACE game, and finally Group 03: composed by 16 undergraduates students which would not use any Gamification technique, just would watch the traditional classes.

Group 3 had more students than the other groups. It can be explained because the whole students used the own notebook to do the experiment. Students of groups 1 and 2, who were using operational system Linux were passed to group 3 because the serious games were developed just for windows distributions.

The classes in which the second experiment was conducted had 40 Science Computer and Information Systems students. They were distributed into 3 groups in the following way: Group 1: composed by 12 undergraduates' students which would use SCRUMI board game, Group 2: composed by 11 undergraduates' students which would use SCRUM IN SPACE game, and finally Group 03: composed by 17 undergraduates' students which would not use any Gamification technique, just would watch the traditional classes.

The experiment was carried out in just one class of 2 hours. First, all students must answer a questionnaire about the main concepts of the SCRUM framework (roughly 15 minutes). This first questionnaire had the objective to define the student's knowledge baseline about the main concepts of the SCRUM framework. This student's knowledge baseline would use to compare the student's gain of knowledge exposed to (i) just traditional classes and (ii) classes AND a specific serious game. So, after they answered the questions, all students watched a SCRUM Classes (roughly 40 minutes). Then, group 3 of the first experiment, which did not use any Gamification technique, just watched the traditional classes, answered the knowledge questionnaire of the SCRUM framework for a second time. Groups 1 and 2 were presented to a specific serious game and played it for roughly 40 minutes. After playing, they answer the same questionnaire about the main concepts of SCRUM Framework again. Then finally, we finish the experiment.

After the experiment was carried out, a paired $t$ hypothesis test would be used to verify if there were significant differences for the Learning Gain BEFORE and AFTER the students be exposed to a specific technique and an Independent $\mathrm{T}$ Test to compare the different techniques.

\subsection{Experiment Results}

During the experiment the students answering a questionnaire with sixteen questions about the framework in order to analyze how much they had absorbed in the V. $19 \mathrm{~N}^{\mathrm{o}} 1$, julho, 2021 RENOTE 
initial contact with the traditional methodology. Such a questionnaire was created using the questions addressed in the game. Then, the students were divided into three groups, where the first played the SCRUMI serious game, the second played the SCRUM in Space serious game and finally the third was exposed only to a traditional class.

After the first and second groups played, respectively, the SCRUMI and SCRUM in Space games, they answered the questionnaire again so that the Learning Gain could be measured. Importantly, the questionnaire was made available online, and both questions and multiple-choice options were shuffled randomly each time the form was accessed.

Analyzing the boxplot (Figure 2) from the correctness of each methodology before and after have contact with the classes or a game, it is clear that the use of serious games showed a direct improvement in students' learning. The difference in success between the two games is small, but when compared to the traditional teaching methodology, the result is significant. The data contained in the chart are shown in Table 1.

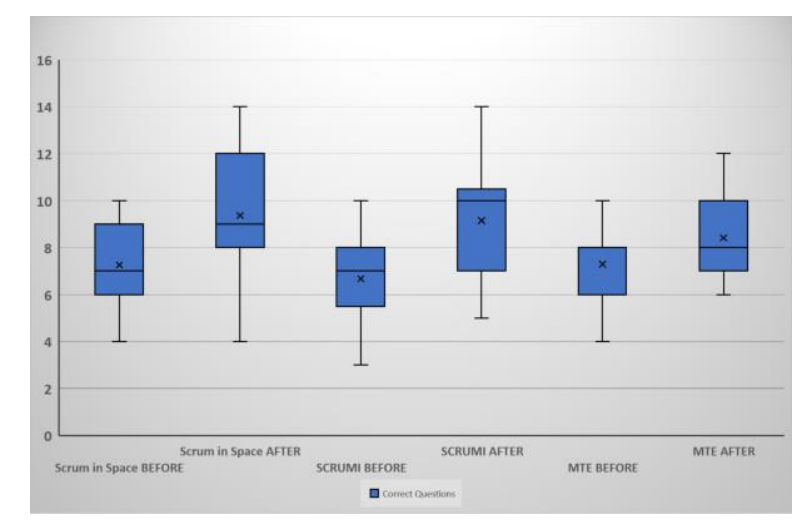

Figure 2 - Boxplot chart of the number of hits in each methodology presented

\begin{tabular}{|c|c|c|c|c|c|c|}
\hline \multicolumn{7}{|c|}{ Descriptive Summary } \\
\hline Groups & TTM After & TTM Before & $\begin{array}{l}\text { TTM + SCRUMI } \\
\text { After }\end{array}$ & $\begin{array}{l}\text { TTM + SCRUMI } \\
\text { Before }\end{array}$ & $\begin{array}{l}\text { TTM + Scrum in } \\
\text { Space After }\end{array}$ & $\begin{array}{l}\text { TTM + Scrum in } \\
\text { Space Before }\end{array}$ \\
\hline Minimum & 6 & 4 & 5 & 3 & 4 & 4 \\
\hline Lower limit & 6 & 4 & 5 & 3 & 4 & 4 \\
\hline First quartile & 7 & 6 & 7 & 5.5 & 8 & 6 \\
\hline Average & 8.411764706 & 7.294117647 & 9.142857143 & 6.6666666667 & 9.368421053 & 7.263157895 \\
\hline Median & 8 & 8 & 10 & 7 & 9 & 7 \\
\hline Third quartile & 10 & 8 & 10.5 & 8 & 12 & 9 \\
\hline Upper limit & 12 & 10 & 14 & 10 & 14 & 10 \\
\hline Maximum & 12 & 10 & 14 & 10 & 14 & 10 \\
\hline
\end{tabular}

The Action tool, an extension of Microsoft Excel, was used to assist in the statistical analysis of the data obtained and verification of the hypotheses. All tests were performed with a $95 \%$ confidence interval.

The first pairs of hypotheses were defined aim to measure if the knowledge gain with each treatment had statistical significance. So, it was used the $\mathrm{T}$ paired test to evaluate the questions hits for the students BEFORE and AFTER the treatments. The Table 2 show the paired T test for the students submitted to Traditional Classes. Despite the Figure 2 show knowledge gain, according to Table 2 its gain was not statistically significant because the P-value was above 0,05 .

However, as shown in Table 2, the results related to students' knowledge gain submitted to the treatments 1 and 2 (students who had played the SCRUMI or Scrum in Space serious game) were very positive, with the P-value being of 0.0013 and 8.06E-05 respectively. So, the null hypothesis was rejected and an alternative hypothesis was accepted for both hypothesis tests, indicating that serious games have greater learning potential than traditional teaching methodologies. 
Table 2 - Paired T test - students' knowledge gain

\begin{tabular}{|llll|}
\hline \multicolumn{1}{|c|}{ Results Paired T Teste } & $\begin{array}{l}\text { Students' Knowledge Gain } \\
\text { submitted to Traditional Classes }\end{array}$ & $\begin{array}{l}\text { Students' Knowledge Gain } \\
\text { submitted to Traditional } \\
\text { Classes AND had played } \\
\text { Scrum in Space }\end{array}$ & $\begin{array}{l}\text { Students' Knowledge Gain } \\
\text { submitted to Traditional Classes } \\
\text { AND had played SCRUMI }\end{array}$ \\
\hline T statistics & -1.732051 & -3.471341 & -4.685176 \\
Degrees of freedom & 32 & 18 & 19 \\
p-value & 0.05188546 & 0.001362326 & $8.06 \mathrm{E}-05$ \\
Average of sample 1 & 7.25 & 7.263158 & 6.65 \\
Average of sample 2 & 8.25 & 9.368421 & 9.35 \\
Standard deviation of the differences & 2.309401 & 2.64354 & 2.577228 \\
Size of samples & 33 & 19 & 21 \\
Alternative hypothesis lower than & 0 & 0 & 0 \\
Confidence level & $95 \%$ & $95 \%$ & $95 \%$ \\
Lower limit & - Inf & - Inf & - Inf \\
Upper limit & 0.01212409 & -1.053606 & -1.703525 \\
\hline
\end{tabular}

This result alone already suggests the game as a possible, supporting tool for conventional classrooms. But, in addition, the experiment shows that both games serve as ancillary practices, consolidating gamification as a possible approach to complementing traditional classroom lessons.

To solidify this idea of games by complementing the classroom and to compare the students' knowledge gain submitted to each treatment, independents T-test were performed comparing the results obtained by the students using the games regarding the students' results exposed only to traditional classroom methodologies. The results, are shown in Tables 3(a) and 3(b).

Table 3 - Independent T test

(a) Is SPI superior to SCRUMI? / Is Scrumi superior to SIP?

\begin{tabular}{|lll|}
\hline \multicolumn{1}{|r|}{ Results Independent T Test } & $\begin{array}{l}\text { Is SIP superior to } \\
\text { SCRUMI? }\end{array}$ & $\begin{array}{l}\text { Is SCRUMI } \\
\text { superior to SIP? }\end{array}$ \\
\hline T statistics & 0.2697746 & 0.2697746 \\
Degrees of freedom & 38 & 38 \\
p-value & 0.3943966 & 0.6056034 \\
Average of Scrum in Space & 9.368421 & 9.368421 \\
Average of SCRUMI & 9.142857 & 9.142857 \\
Standard deviation Scrum in Space & 2.793057 & 2.793057 \\
Standard deviation SCRUMI & 2.495711 & 2.495711 \\
Standard deviation grouped & 2.640736 & 2.640736 \\
Scrum in Space size & 19 & 19 \\
SCRUMI size & 21 & 21 \\
Alternative hypothesis grater than & 0 & 0 \\
Confidence level & $95 \%$ & $95 \%$ \\
Lower limit & -1.184096 & -1.635224 \\
Upper limit & - Inf & - Inf \\
\hline
\end{tabular}

To test the first pair of hypotheses, two independent T-tests were performed comparing results obtained by the students after playing both games, testing both the SCRUM in Space hypothesis to be superior to SCRUMI and the SCRUMI hypothesis to be superior to SCRUM In Space, as shown in Table 3(a).

However, in both tests, nothing can be concluded by comparing the games, as both results have a P-value above 5\%. The end result was very similar, and statistical tests are not able to prove the hypothesis. Therefore, comparatively, it is not possible to say which game presented the most significant result.

Now we tested two other hypotheses related to SIP and SCRUMI be superior to traditional classroom. The results are shown in Table 3(b). Both hypothesis tests shown that the serious games are superior to traditional classroom.

V. $19 \mathrm{~N}^{\mathrm{o}} 1$, julho, 2021

DOI: https://doi.org/10.22456/1679-1916.118432

RENOTE 


\section{Conclusion}

The main contribution of this work is to test two different strategies of serious games, to compare them with each other, and also to compare them with the traditional teaching methodology.

The experiment was carried out, with an expressive number of undergraduate students (73) divided into three groups. The hypotheses test show that: (i) the use of gamification could increase significantly the knowledge gained by the students in comparison with the traditional classroom, (ii) There were no significant difference in the knowledge gained by the students in the games used in these experiments, (iii) there were no significant statistical difference between knowledge gained BEFORE and AFTER the students watched the classes, and finally (iv) there were significant statistical difference between knowledge gained BEFORE and AFTER the students played the games.

The learning gain presented by the students directly indicates a benefit of using the tools. The use of games as an auxiliary tool to traditional teaching methods can be a way of ensuring that the concepts presented in classrooms are efficiently absorbed by students. Transition, however, shall not be immediate, as the importance of teachers/professors and classrooms, even at a distance, remains proven. However, this should not serve as an impediment to game development in education, but rather as a new tool for teachers to modify and adapt teaching in a more efficient fashion.

\section{References}

J. P. Gee. Deep Learning Properties of Good Digital Games: How Far Can They Go? in Serious Games: Mechanisms and Effects, $1^{\text {st }}$ ed., NY, USA: Routledge Taylor \& Francis Group. 2009, ch. 5, pp. 10-24. [Online]. Available: https://www.taylorfrancis.com/books/e/9780203891650/chapters/10.4324/ 9780203891650-15.

K. M. Kapp. The Gamification of Learning and Instruction: Game-based Methods and Strategies for Training and Education. $1^{\text {st }}$ ed., Wiley \& Sons, 2012.

R. Morsi and S. Mull. Digital Lockdown: A 3D Adventure Game for Engineering Education. 2015 IEEE Frontiers in Education Conference (FIE). El Paso, TX. [Online]. Available: https://ieeexplore.ieee.org/document/7344072.

Newzoo. Demographics of Gamers. Based on research in 32 Countries. Aug., 2020. [Online]. Available: https://platform.newzoo.com/key-numbers.

A. D. de Souza, R. D. Seabra, J. M. Ribeiro and L. E. da S. Rodrigues. (2017, May). SCRUMI: A Board Serious Virtual Game for Teaching the SCRUM Framework. 2017 IEEE/ACM 39 ${ }^{\text {th }}$ International Conference on Software Engineering Companion (ICSE-C), Buenos Aires. [Online]. Available: https://ieeexplore.ieee.org/document/7965344.

S. Vanbecelaere, K. Van de Berghe, F. Cornillie, D. Sasanguie, B. Reynvoet and F. Depaepe. The effects of two digital educational games on cognitive and non-cognitive math and reading outcomes. Computers and Education, vol. 143, article 103680, Jan, 2020. Acessed on May, 01, 2020, DOI: 10.1016/j.compedu.2019.103680, [Online].

D. Vlachopoulos and A. Makri. The effect of games and simulations on higher education: a systematic literature review. International Journal of Educational Technology in Higher Education, vol.14, article number 22, Jul. 10, 2017. Acessed on: Jul, 29, 2020, DOI: https://doi.org/10.1186/s41239-017-0062-1, [Online].

K. Werbach; D. Hunter. For the win: how game thinking can revolutionize your business. Philadelphia: Wharton Digital Press, 2012. 